\title{
Ontologies, socio-technical transitions (to sustainability), and the multi-level perspective
}

\author{
Frank W. Geels \\ SPRU, Science and Technology Policy Research, University of Sussex, United Kingdom
}

\section{A R T I C L E I N F O}

\section{Article history:}

Received 1 August 2008

Received in revised form 1 December 2009

Accepted 1 January 2010

Available online 21 February 2010

\section{Keywords:}

Foundational ontologies

Socio-technical transitions

Multi-level perspective

Sustainability

\begin{abstract}
A B S T R A C T
Using recent criticisms and suggestions regarding the multi-level perspective as stepping stones, the article aims to enhance the reflexivity in transition debates regarding social theories. To that end, the article discusses seven social science ontologies (rational choice, evolution theory, structuralism, interpretivism, functionalism, conflict and power struggle, relationism), their assumptions on agency and causal mechanisms, and their views on socio-technical transitions and environmental sustainability. The second goal is to position the multi-level perspective on transitions with regard to these ontologies and to identify directions for theoretical extensions. The MLP is characterized not as a grand or unifying theory, but as a middle range theory that makes crossovers to some ontologies and not to others.
\end{abstract}

(C) 2010 Elsevier B.V. All rights reserved.

\section{Introduction}

New environmental problems, such as climate change, biodiversity and resource depletion, have gained prominence on the political agenda in the 1990s and early 2000s. These pervasive problems differ in scale and complexity from the environmental problems of the 1970s and 1980s, such as water pollution, acid rain, local air pollution and waste problems. While the latter problems have been addressed fairly well with incremental clean technologies, responses to the new environmental problems require more substantive 'transitions' in the coming decades, i.e. major changes in energy, transport, and agri-food systems (Elzen et al., 2004; Wiskerke and Van der Ploeg, 2004; Van den Bergh and Bruinsma, 2008; see also the papers in this special issue). ${ }^{1}$ These system changes are labelled 'socio-technical' because they not only entail new technologies, but also changes in markets, user practices, policy and cultural meanings (Geels, 2004).

Socio-technical transitions to sustainability do not come about easily, because existing energy, transport, housing and agri-food systems are stabilized by lock-in mechanisms that relate to sunk investments, behavioural patterns, vested interests, infrastructure, favourable subsidies and regulations (Unruh, 2000). The multi-level perspective (Rip and Kemp, 1998; Geels, 2002; Geels, 2004; Geels and Schot, 2007) is a framework for understanding sustainability

E-mail address: f.w.geels@sussex.ac.uk.

1 Socio-technical transitions to sustainability are also addressed in special issues in Technology Analysis \& Strategic Management (2008, 20(5)) and in Technological Forecasting and Social Change (2005, 72(6); 2009, 76(2)). transitions that provides an overall view of the multi-dimensional complexity of changes in socio-technical systems. The MLP distinguishes three analytical levels: niches (the locus for radical innovations), socio-technical regimes, which are locked in and stabilized on several dimensions, and an exogenous socio-technical landscape. These 'levels' refer to heterogeneous configurations of increasing stability. The MLP proposes that transitions, which are defined as regime shifts, come about through interacting processes within and between these levels. Transitions do not come about easily, because existing regimes are characterized by lock-in and path dependence, and oriented towards incremental innovation along predictable trajectories. Radical innovations emerge in niches, where dedicated actors nurture alignment and development on multiple dimensions to create 'configurations that work' (Rip and Kemp, 1998). These niche-innovations may break through more widely if external landscape developments create pressures on the regime that lead to cracks, tensions and windows of opportunity. Subsequent struggles between niches and regimes, and possible replacement, take place on multiple dimensions (e.g. markets, regulations, cultural meanings, infrastructure) and are enacted by interpretive actors that fight, negotiate, search, learn, and build coalitions as they navigate transitions.

Although the MLP has been taken up as a useful framework, recent Research Policy articles articulated criticisms and suggested possibilities for extension. Smith et al. (2005) argued that the MLP could pay more attention to agency and the role of power in socio-technical transitions. Genus and Coles (2008) repeated this message, and further suggested greater incorporation of constructivist approaches, such as social construction of technology (SCOT), actor-network theory (ANT) and constructive technology 
assessment. Markard and Truffer (2008) argued that incorporation of the technological innovation systems (TIS) approach into the MLP might result in an "overarching conceptualization" and "encompassing theoretical framework of socio-technical change" (p. 612).

Other critics took issue with the presumed dominance of the MLP in sustainability transition discussions and argued for exploring other social science theories. Shove and Walker (2007: 768), for instance, argue for "loosening the intellectual grip of 'innovation studies', for backing off from the nested, hierarchical multi-level model as the only model in town, and for exploring other social scientific, but also systemic theories of change" (italics in original, FG). Unfortunately, they did not explicate which systemic theories of change they had in mind (the Shove and Walker paper in this special issue advocates practice theories). Hence, one part of this article aims to explore what general social science theories have to offer with regard to transitions (to sustainability) and introduce their insights more systematically into the study of socio-technical transitions and perhaps also into innovation studies more generally. ${ }^{2}$ This social theory exploration is deliberately broad because of the multi-dimensionality of sustainability transitions.

The article's second goal is to evaluate and, where fruitful, further develop the suggestions from other critics who suggested that the MLP should be extended to better accommodate power theories, interpretivism (SCOT), relationism (ANT) and (innovation) systems theory. These suggestions come from very different social theory traditions, with different ontological assumptions about causal agents and causal mechanisms. While some of these theories may suggest areas for extension of the MLP, it cannot be taken for granted that all theories can or should be incorporated. The article thus aims to enhance reflexivity about the relations between the MLP and general social theories, to investigate the (im)possibilities of crossovers, and to identify possible directions for theoretical extension of the MLP.

This article thus addresses two sets of questions.

1. What are the main general theories (ontologies) in social science? What are their assumptions? What do they say, or what implications can be derived, with regard to socio-technical transitions and sustainability?

2. How do these ontologies relate (or not) to the MLP? What insights do they offer for theoretical extensions of the MLP?

Section 2 addresses the first question by discussing the assumptions of seven foundational ontologies and their conceptualization of transitions (to sustainability). Section 3 addresses the second question and positions the MLP as a crossover approach between evolution theory and interpretivism. It further argues that the MLP makes no crossovers to rational choice and functionalism, and can be fruitfully extended with insights from structuralism and power theories. The relationship with relationism is ambiguous, hovering between inspiration and problems. Concluding remarks in Section 4 argue that innovation studies is well placed to address sustainabil-

\footnotetext{
2 The reason for the latter ambition is the following tension in innovation studies. On the one hand, the editors of Research Policy, the flagship journal for innovation studies, position RP "at the intersection of cognate social science disciplines (in particular, economics, management, policy studies and political science, organisational science, sociology, and history of technology and innovation" (Martin et al., 2009: 695 ). On the other hand, Fagerberg and Verspagen (2009) suggest that the community of innovation studies consists of $58 \%$ economists, $9 \%$ engineers, $8 \%$ geographers, $6 \%$ management, $5 \%$ sociology and others (psychology, history, humanities, policy, S\&T studies). While the article's method based on self-identification probably leads to an under-representation of science and technology studies scholars and organization/management/business scholars interested in innovation, their findings do point to a tension between RP's multi-disciplinary ambitions and the dominance of economics.
}

ity transitions, but may also require some conceptual broadening to address the normativity and directionality of these transitions. The article's multi-disciplinary discussion aims to assist this reflexive broadening.

\section{Foundational ontologies and socio-technical transitions to sustainability}

Because socio-technical transitions are multi-dimensional phenomena, they can be studied from various angles by different disciplines. Every approach is underpinned by (often implicit) ontologies, i.e. foundational assumptions about the nature of the (social) world and its causal relationships (e.g. Burrell and Morgan, 1979; Ritzer, 1980; Collins, 1994). Ontologies postulate a certain causal agent and primary causal mechanism. "These mechanisms are empirically underspecified, exist outside specific spatial and temporal boundaries, and cannot be directly observed.(...) they are treated as ontologically primitive causes of outcomes and associations" (Mahoney, 2004: 461). Studies of transitions thus inevitably highlight certain aspects and background others. The following subsections substantiate and elaborate this claim, discussing for different ontologies: (a) their core assumptions (causal agents and mechanisms) and some exemplars (theories that embody the particular ontology) that are relevant for the MLP, (b) their conceptualization of socio-technical transitions, (c) their understanding of sustainability transitions. Expanding on Mahoney, I will discuss seven ontologies (Table 1$)^{3}$

One qualifier is that not all of these ontologies explicitly address sustainability or transitions in their entire socio-technical complexity. In those instances, the discussions of issues (b) and (c) are my interpretations of the implications of the ontologies for these issues. Another qualifier is that space limitations require discussions to be stylized and focused on the basic logics and core assumptions of different ontologies. While this focus is useful to highlight their different views of the world in general and transitions in particular, the limitation is that further adjustments, elaborations and nuances in the literature are not discussed (although sometimes alluded to). This also means that theories and approaches that make crossovers between ontologies are not discussed in Section 2. While Section 3 discusses how the MLP makes crossovers to various ontologies, I thus recognize that the MLP is not the only approach that does so. The third qualifier concerns the choice of particular theories and authors as exemplars of ontologies. I have generally chosen theories from sub-disciplines within the STI-field (economics of innovation, STS, some strategy literatures). I further selected seminal authors (e.g. Schumpeter, Marx, Porter, Elias, Freeman, Bijker) and/or scholars that explicitly engaged with the transitions and sustainability debate. Given the broad scope of social science traditions and relevant authors, my choices are of course open to debate.

\subsection{Rational choice}

\subsubsection{Causal agents, causal mechanisms, exemplars}

The causal agents in rational choice are self-interested, utilitarian individuals who use instrumental rationality as mechanism to choose the course of action that maximizes utility with regard to their (material) preferences, which are considered fixed and given. Actors choose between alternatives that are assumed to readily exist (as a given choice-set). Actors are further assumed to have full and free information about the alternatives and the consequences of their choices. Under these conditions, actors can make costbenefit calculations to rationally determine the best alternative.

\footnotetext{
3 Mahoney (2004) distinguished functionalism, rational choice, power, neoDarwinian and cultural ontologies.
} 
Table 1

Foundational assumptions in different ontologies (expanded from Mahoney, 2004: 463).

\begin{tabular}{|c|c|c|}
\hline & Causal agent & Causal mechanism \\
\hline Rational choice & Individual, self-interested actors & Decentralized choice by instrumental rationality \\
\hline Evolution & Agents in population & Variation (search), selection, retention \\
\hline Structuralism & Taken for granted deep structures (belief systems) & $\begin{array}{l}\text { Deep structures' operate 'behind the backs' of actors, influencing } \\
\text { their views and preferences }\end{array}$ \\
\hline Interpretivism/constructivism & Individual actors with varying ideas and interpretations & $\begin{array}{l}\text { Social interaction, construction of shared meaning, sense-making, } \\
\text { learning, debates }\end{array}$ \\
\hline Functionalism (systems theory) & Social system & Actors fulfil system needs, enacting roles, tasks and norms \\
\hline Conflict and power struggle & Collective actors (groups, classes) with conflicting interests & Conflict and power struggle between different collective actors \\
\hline Relationism & Networks and ongoing relations & Interaction, co-construction, translation, alignment \\
\hline
\end{tabular}

Neo-classical economics is the main exemplar, focusing on rational resource allocation decisions under conditions of scarcity. Consumers allocate their budgets on purchase decisions to maximize utility, while producers invest resources in production and sales processes to maximize profits. Macro-order is assumed to arise from the aggregation of decentralised choices, with the market and price signals acting as coordinating mechanism (the 'invisible hand'). In an economy where markets are complete (full information) and competitive, aggregated decisions lead to an equilibrium that is welfare maximizing and Pareto-efficient. ${ }^{4}$

Rationalist approaches in the strategy field form another exemplar of the rational choice ontology, although they usually replace 'full rationality' with 'bounded rationality' assumptions (because strategy would not be needed if all decisions could be fully calculated). ${ }^{5}$ The planning school (Ansoff, 1965), for instance, sees strategy as a formal-analytical process of steps that specifies goals, tasks, targets, deliverables, budgets and controls that check progress. In the positioning school strategy is about finding, occupying and defending favourable positional advantages in external industry structures. Porter (1980), for instance, suggests that firms need to choose between three rational positions (cost leadership, product differentiation, and differentiation focus) that can be defended against five industry forces (competitors, threat of new entrants, threat of substitute technologies, bargaining power of buyers, bargaining power of suppliers). Both schools conceptualize strategy as a rational and deliberate process of data-collection, analysis and choice of best strategy, which precedes implementation. Implementation is seen as a managerial process that involves tasks, incentives and controls.

\subsubsection{Transition dynamics}

Neo-classical economics conceptualizes transitions as changes in the economic structure (e.g. the shift from labour to capital), which are driven by changing prices of production factors and outputs, in response to which firms change their investment strategies and consumers change their purchase decisions. Changes in factor costs (labour and capital in neo-classical theory, knowledge in endogenous growth theories, and natural resources in environmental economics) lead to relative shifts along the production function (Butter and Hofkes, 2006). Transitions can also be related to changes in the production function, which are caused by a change in production technology. While traditional neo-classical models treated technical change as an exogenous process, endogenous growth theorists made technology more endogenous, describing it as the result of R\&D investments, knowledge creation, learning-by-doing and knowledge spillovers (Romer, 1986). Rising prices of a production

\footnotetext{
${ }^{4}$ No person can be made better off without making at least one person worse off.

${ }^{5}$ Rationalist approaches were dominant when the strategy discipline emerged in the 1960s. Since then the strategy field has diversified into various directions, with scholars also developing theories that start from other ontological assumptions. Mintzberg et al. (1998), for instance, distinguish ten different schools in strategic management.
}

factor will lead firms to invest in innovations that reduce the use of this production factor, and gradually lead to adjustments in the economic production structure. Timelags in the adoption of 'best practice' machines are explained by the vintage, which argues that the capital stock of firms consists of machines of different ages (vintages) with different operating costs. Although old machines may be less efficient than 'best practice' machines, firms continue to use them when their revenues cover their operating costs or until investments' costs have been earned back (Kemp, 1997). Because new vintages are gradually added to the existing capital stock, technological change is conceptualized as an incremental process with time lags. In sum, neo-classical economics conceptualizes transitions as gradual adjustment to changing prices.

The strategy planning school has little to say about transitions, because it assumes stable conditions where plans can be made and administered. The positioning school, especially as developed in some of the industrial organization literature, addresses transitions in terms of new entrants and new technologies that contest the positions of existing firms and technologies. Much of this firm-oriented technological discontinuity literature analyzes the (rational) factors that influence this struggle. Attackers are thought to have advantages because they are more agile and flexible in responding to new technologies than incumbent firms for whom the initial small markets do not generate enough profits and return-on-investment (Foster, 1986; Christensen, 1997). Other strategy scholars suggest, however, that incumbent firms may successfully defend their strategic positions when they possess relevant complementary assets such as specialized manufacturing capability, experience with large-scale test trials, access to distribution channels, service networks, or complementary technologies (Tripsas, 1997; Rothaermel, 2001). In those instances, new entrants are dependent on incumbents for the upscaling, commercialization or diffusion of radical innovations, allowing the latter to negotiate favourable positions in strategic alliances.

\subsubsection{Sustainability transitions}

In a neo-classical view environmental problems are caused by market failures, because producers are causing negative effects (externalities) that are not reflected in the price, and by the public good character of a clean environment (which leads to 'free rider' effects that limit 'green' investments). To stimulate transitions in sustainable directions, neo-classical economists therefore argue that the conditions under which the markets operate should be changed (Butter and Hofkes, 2006). Governments can address market failures with policy instruments such as environmental taxes, subsidies and tradable permits. The internalization of environmental costs leads to price changes that will subsequently lead to R\&D investments and capital investments that will transform economic structures in sustainable directions.

The strategy literature sees sustainability transitions as strategic dilemmas for firms, who have to balance the risks and opportunities associated with (sometimes multi-million dollar) investments. On the one hand, it may be rational to postpone 'green' invest- 
ments because of future uncertainties in government regulations, price fluctuations, the degree to which environmental concerns translate into a willingness to pay more for green products, and the emergence of 'green' markets (Rugman and Verbeke, 1998). Because these uncertainties complicate rational calculations of return-on-green-investment, it may be rational to wait for more clarity. On the other hand, 'green' technology leaders may benefit from first mover advantages (such as brand recognition, creation of market positions, technology lead, creation of patent barriers) that create favourable positions in future 'green' innovation races. Firms that have a 'green' lead may also convince policy makers to issue stricter regulations and thus impose 'imitation costs' on competitors (Puller, 2006). Environmental sustainability thus forms a dimension of strategic and competitive games.

\subsection{Evolution theory}

\subsubsection{Causal agents, causal mechanisms, exemplars}

The causal agent in evolution theory is a population of heterogeneous agents. Micro-evolution deals with the mechanisms of variation, selection and retention that underlie genealogical lineages (trajectories). For socio-technical change, evolutionary economics (EE), which focuses on firms, innovation, and market competition, is especially relevant (Nelson and Winter, 1982). The conceptualization of agents builds on the behavioral theory of the firm (Cyert and March, 1963), in which actors are boundedly rational, because of information processing limitations. Actors therefore use routines, heuristics, standard operating procedures in decisionmaking and day-to-day problem solving. Firms are adaptive agents that engage in problemistic search to find solutions to these problems. Search processes such as R\&D, which generate innovations, are also guided by routines such as search heuristics and resource allocation routines. Search tends to be close to existing routines, localized and incremental: "the probability distribution of what is found is concentrated on techniques close to the current one" (Nelson and Winter, 1982: 211). This means that actors do not optimize, but satisfice: they do not explore the whole search space, but stop searching when they find an alternative that seems satisfactory. While firms in an industry share particular general routines (which add up to technological regimes), they differ in specific routines and capabilities, and therefore search in (slightly) different directions. Performance feedback, often via market selection, ultimately determines which innovations are retained and stored in the firm's routines. Micro-evolution thus conceptualizes change as incremental adaptation, which proceeds through trial-and-error and behavioural learning.

\subsubsection{Transition dynamics}

Macro-evolution deals with long-term change patterns such as transformation, speciation, ecological invasion, punctuation and extinction. Criticizing the gradual adjustment view of neo-classical economics, Schumpeter (1939), for instance, argued that economic "evolution is lopsided, discontinuous, disharmonious by nature... studded with violent outbursts and catastrophes... more like a series of explosions than a gentle, though incessant, transformation" (p. 102). The core drivers for such transitions are radical innovations, which emerge endogenously from the economic system by entrepreneurial action, and lead to creative destruction.

While Schumpeter was interested in broad socio-economic change, evolutionary economics since the 1980s focused more specifically on the role of technical change and innovation in firmand industry-level competition. Some of this work conceptualizes transitions as technological discontinuities, with new entrants struggling against incumbents. It argues that novelties and radical innovations emerge endogenously through speciation, niches and entrepreneurship (Cattani, 2006). Although the initial muta- tion may be small, different selection pressures in the isolated niche can set the innovation on a divergent trajectory that eventually results in a product that is substantially different from the original lineage (Levinthal, 1998; Schot and Geels, 2007). Incumbent firms tend to overlook or ignore radical innovations, because existing competences and routines blind them to alternatives outside their focus (Nelson and Winter, 1982). Because technological regimes or paradigms lead firms to explore the technical search space in directions that are close to existing routines and competencies, innovations tend to be incremental adding up to predictable technical trajectories (Dosi, 1982). A common pattern is that outsiders and entrepreneurs nurture and develop radical innovations in niches 'below the surface' of incumbent regime actors. If investments and learning processes improve their price/performance characteristics, radical innovations may subsequently break out of their initial niches into mainstream market, capturing incumbents by surprise and out-competing them. While this pattern does occur, it is not a law. Incumbents can sometimes reorient themselves and develop radical novelties that cannibalize their investments in existing technologies (Chandy and Tellis, 1998).

A broader approach to transitions focuses on shifts in technoeconomic paradigms (TEP) that span the entire economy (Freeman and Perez, 1988). TEPs refer to configurations of pervasive technologies, methods of production, economic structures, institutions and beliefs that are stable for long periods because certain 'key factors' offer great benefits. New technologies, which emerge in particular sectors, initially face "a degree of mismatch between the techno-economic sub-system and the old socio-institutional framework" (p. 59). Further breakthrough occurs when the old 'key factor' runs into problems and when the new technology acquires dynamics of its own. The breakthrough is accompanied by broader socio-institutional changes. The Freeman and Perez (1988) approach has been criticized for technological determinism, because of the suggested causality that techno-economic forces do the initial acting and the socio-institutional framework the subsequent reacting. Freeman and Louçă (2001) therefore refined the approach by distinguishing five equally important 'sub-systems': science, technology, economy, politics and culture. These sub-systems interact, but also have their own dynamics and fluctuations (e.g. political cycles, business cycles, technological trajectories, cultural movements). Major mal-adjustments between sub-system dynamics lead to economic crises and opportunities for the breakthrough of major innovations and new TEPs. This improved approach is similar to the MLP in its emphasis on alignments between heterogeneous processes: "It is essential to study both the relatively independent development of each stream of history and their interdependencies, their loss of integration, and their reintegration" (Freeman and Louçă, 2001: 127).

\subsubsection{Sustainability transitions}

In technological discontinuity approaches, transitions towards sustainability are driven by the development of 'green' technologies. Following an evolutionary logic, the process consists of interactions between changes on the variation side (R\&D investments, competence building, knowledge flows, price/performance improvements in 'green' technologies) and in the selection environment (e.g. stricter environmental regulations or changes in user preferences).

Work on 'green' techno-economic paradigms (Freeman, 1992) emphasises the 'green' potential of the ICT-paradigm for energy and material savings in existing products and production processes (e.g. better monitoring and control, miniaturization, teleworking, teleconferencing). But in his conclusions, Freeman (1992: 207) acknowledges that this is not sufficient: "the incremental improvement of existing systems will not be enough to achieve the scale of reduction in energy and materials consumption which will be 
needed in the industrial countries during the twenty-first century. Radical innovations will be needed including new transport, construction and industrial systems". Although he does not spell out the dynamics of these green system innovations, Freeman does highlight the importance of long-term policy frameworks, highlevel government support, long-term technology programs with a variety of participants, and strong support of public opinion.

\subsection{Structuralism}

\subsubsection{Causal agents, causal mechanisms, exemplars}

Structuralism perceives actors as part of social collectives that share particular belief systems, symbolic sets and cultural categories that provide meaning and a sense of direction. These cognitive 'deep structures' are therefore the causal agents, operating 'behind the backs' of individual actors and defining what is desirable, acceptable and legitimate. One examplar is structural anthropology, which aims to uncover the cultural 'deep grammar' made up of 'binary' opposites (Lévi-Strauss, 1963).

Forms of structuralist thinking are also present in neoinstitutional sociological theory (Powell and DiMaggio, 1991; Scott, 1995), which focuses on shared cognitive frameworks and belief systems. Conformity to cognitive institutions confers legitimacy, which help firms to create public acceptance, political protection and venture capital mobilization (Suchman, 1995). In institutional environments, organizations thus compete for social fitness rather than economic efficiency. This struggle for social legitimacy thus forms a mechanism that links organizational behaviour with broader belief systems and public opinion. While early theorists emphasised isomorphism, conformity and stability, institutional scholars have also begun to investigate variety, change and strategic responses to institutional pressures (Greenwood and Hinings, 1996).

\subsubsection{Transition dynamics}

The core process for transitions is a shift in belief systems, ideologies and public opinion. Such shifts not only influence consumer preferences and values but also create credibility pressure on and legitimacy for policy makers to introduce strict regulations. In his famous switchmen metaphors, Weber argued that shifts in societal beliefs, ideas and ideologies may influence the direction of societal development. "Not ideas, but material and ideal interests directly govern men's conduct. Yet very frequently the 'world images' that have been created by 'ideas' have, like switchmen, determined the tracks along which action has been pushed by the dynamic of interest" (Weber, 1946: 280). Also macro-historians suggest that ideological and cultural changes often create an initial impetus for societal change. Braudel (1993), for instance, distinguishes three phases in the transition to welfare states: (1) the ideological phase (1815-1870), where social reformers drew attention to poverty-related problems and developed new ideas and vocabularies with words like industrialist, capitalist, exploitation, proletariat, the masses, and Socialism; (2) the phase of mobilization (1870-1914), where militant labor (trade unions, new political parties) engaged in power struggles to further their interests, (3) the political/governmental phase (after World War I), where the State increasingly implemented new laws, programs and social measures. While this suggestion resonates with structuralism, which argues that large-scale changes start with new ideas, ideologies and discourses, it also indicates that realization of change also requires spillovers to other domains (e.g. politics, economics).

\subsubsection{Sustainability transitions}

In a structuralist view, two macro-agendas and discourses currently struggle for the future of the 21 st century: (1) neo-liberalism and globalization (with associated notions such as international

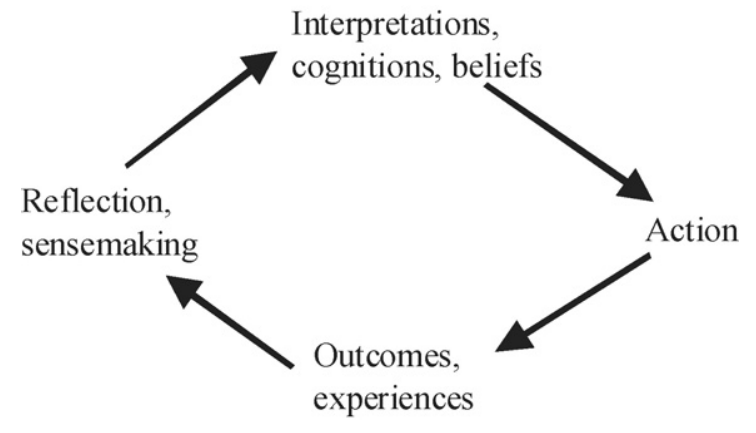

Fig. 1. Cognitive learning cycle (adapted from Kolb, 1984).

competitiveness, economic growth, limited regulation, marketbased processes, privatization, individual responsibilities), and (2) sustainable development and social transformation (ecological modernization, risk society, stronger government roles, corporate social responsibility, public participation, democratization). While the first macro-agenda has dominated since the 1980s, sustainability transitions may require a shift towards the second agenda. Although new vocabularies and words have appeared (e.g. 'green', 'sustainable development', 'ecological footprint', 'carbon trading', 'environmental impact assessment', 'lifecycle analysis'), such a shift would require a greater sense of urgency about the new environmental problems and widespread beliefs that radical 'green' innovations are feasible and desirable. More radical cultural shifts are advocated by ‘deep ecology' and eco-centrist approaches (Katz et al., 2000), which reject 'Modernism' (based on economic growth, science, technical progress) and advocate 'deep green' life styles, localism and decentralized renewable energy options.

\subsection{Interpretivism/constructivism}

\subsubsection{Causal agents, causal mechanisms, exemplars}

The interpretive/constructivist ontology is, like structuralism, interested in 'meaning', but it takes a more agency-oriented approach. Rooted in cognitive psychology, symbolic interactionism, and ethnomethodology, interpretivism/constructivism perceives actors as creative and continuously engaged in sense-making (Weick, 1979). Interpretation precedes decisions and strategies, because actors need to make sense of data, signals and situations before they take action. While evolutionary theory assumes 'bounded rationality' (based on information processing limitations), interpretivism/constructivism focuses on intersubjective sense-making and symbolic constructions of reality through which people create shared interpretations (Berger and Luckman, 1967). Interactive mechanisms are conversations, debates, negotiations, and learning processes. Learning not only includes behavioural learning (learning-by-doing which evolutionary theories operationalize through search and performance feedback), but also cognitive learning (which emphasizes action, reflection and sensemaking) (Schön, 1983; Gavetti and Levinthal, 2000). Cognitions and interpretations are continuously reproduced and/or modified because cognitive learning (and sense-making) is ongoing process with actors discussing and interpreting outcomes and experiences (Fig. 1). Accumulation of experiences or data within cognitive frames constitutes first-order learning, while alteration of cognitive frames constitutes second-order learning (Argyris, 1976).

Giddens's (1984) structuration theory is an interpretive approach that makes crossovers to structural ontologies, defining structures somewhat abstractly as 'rules and resources'. Actors are seen as knowledgable agents who actively draw upon rules in concrete interactions. They interpret and tailor rules to the demands of 
specific contexts. While actors are seen as embedded in rules, structuration theory thus maintains active and interpretive dynamics.

\subsubsection{Transition dynamics}

Early phases of transitions are characterized by uncertainty and 'interpretative flexibility' around radical innovations. The social construction of technology (SCOT) approach, for instance, argues that social groups attach different meanings to new technologies (Bijker, 1995), leading to clashing opinions and heated debates, which create uncertainty and prevent full commitments from policy makers, consumers, and investors. Transitions gather pace when socio-cognitive processes converge ('closure') into shared views and agreement about the best way forward. Transition management advocates (Rotmans et al., 2001) suggest that this process can be facilitated through participatory visioning exercises, multistakeholder learning processes, and societal debates.

Transitions may also involve changes in the beliefs of incumbent actors. As long as they believe that problems can be met within the existing regime, their investments and innovation activities remain targeted towards incremental innovations (single loop learning). Strategic reorientation towards radical niche-innovations therefore requires the questioning and destabilisation of existing beliefs (unfreezing), moving/changing (double loop learning), and refreezing into new routines (Lant and Mezias, 1992) (see also Section 3.2).

\subsubsection{Sustainability transitions}

Sustainability transitions are hindered by the absence of shared visions. Sustainability is an ambiguous and contested concept. Actors not only have different interpretations of the right balance between social, economic and environmental sustainability, but also have different rankings of environmental problems and hold different views about the (dis)advantages of particular solutions and the most appropriate policy packages. Disagreement and debate are thus inevitable because: “(...) sustainability concerns nothing less than the future direction of human civilisation. Is there anything more likely to generate discussion and dissent than this? Even if society broadly agrees on what a more sustainable future would look like, the underlying causes of (and hence remedies for) unsustainability are likely to be so deeply contested that consensus on even the most basic of policy packages will probably always remain elusive" (Jordan, 2008: 28). There is not one 'green' innovation around which opinions coalesce. Instead, there are multiple 'green' options, which are appraised differently by various social groups. ${ }^{6}$ Sustainability transitions should therefore not be seen as technocratic challenges, but as deliberative social learning processes (Stirling, 2007). Double loop learning, aimed at changing existing beliefs, can be facilitated by the participation of regime actors in 'green' experimental projects that stretch existing routines and stimulate reflexivity (Bos and Grin, 2008).

\subsection{Functionalism}

\subsubsection{Causal agents, causal mechanisms, exemplars}

The causal agent in functionalism is the social system. The causal mechanism is the fulfillment of system needs/goals by actors who fulfil functions, tasks or roles. For general social systems Parsons (1951) distinguished four core functions (AGIL) that need fulfilment to maintain stable continuation: (1) Adaptation: interaction with

\footnotetext{
${ }^{6}$ While some groups, for instance, value wind energy, because it produces renewable electricity, other groups dislike wind turbines because they kill birds, disturb open landscapes, create noise for local residents, and are an intermittent energy source, which makes electricity grids unstable.
}

nature and produce commodities, (2) Goal-attainment: setting goals and implementing appropriate decisions, (3) Integration: creation of harmony and convergence through shared values and norms, (4) Latency: pattern maintenance over time through socialization of new members. Modern societies have developed industries, markets, science and technology for Adaptation; political institutions for Goal-attainment; religion and civil society for Integration; and schools and families for Latency. Although functionalism assumes a division of tasks and responsibilities, all groups are impelled to contribute to the overall goal: stable functioning of the social system.

In the 1960s and 1970s, Parson's structural-functionalism was criticized for reification, teleology, an over-socialized view of actors, and a bias towards consensus and stability. These criticisms tainted the reputation of functionalism and made it 'suspicious' in social theory. ${ }^{7}$ Later scholars (e.g. Mouzelis, 1995) argued, however, that the baby may have been thrown out with the bathwater and that the suspicion of functionalism makes it difficult to ask questions about larger social constellations. Neo-functionalists therefore developed more dynamic frameworks that allow more agency and include crossovers to interpretivism, structuralism and conflict theories. While functionalism often relies on external shocks and internal tensions to explain change (see below), neo-functionalists argue that:

"General strain and disequilibrium is not enough. (...). Strains do not 'reveal themselves'; they must be defined before they can be acted upon. This definition will depend not just on material position, but on contingent cultural sensitivities, and will develop in an atmosphere of contingent conflict. (...) Strain is a product of communication and collective definition. (...) Institutional entrepreneurs must 'persuade' others, then, that an important social problem exists which deserves immediate attention" (Alexander and Colomy, 1985: 17).

Dynamic system theories also emerged from the natural and technical sciences, e.g. system dynamics, integrated systems theory, soft systems approaches and complex systems theory (Holland, 1995; Kauffman, 1995). Whereas functionalism distinguishes separate domains and sub-systems, these system theories address dynamic interactions between system elements. Causal interaction mechanisms tend to be abstract and metaphorical, e.g. negative feedbacks that stabilize systems, positive feedbacks that amplify initially small changes (resulting in non-linear chaotic behaviour), self-organization, emergence (higher-level system properties arise from component interactions), attractors (that describe dynamic equilibrium states towards which systems tend), tipping points (thresholds beyond which a system leaves its 'basin of attraction'). While some claim that complex systems theory can be applied to economic, ecological and social systems (Holling, 2001), the operationalization of actors tends to be abstract and with few concrete sociological characteristics (Horgan, 1995). Morel and Ramanujam (1999) therefore characterize complexity theory as a heterogeneous ensemble of exciting observations, which, however, need further operationalization beyond the metaphors for broader application in the social domain.

\subsubsection{Transition dynamics}

In structural-functionalism, change is caused by external disturbances that disrupt equilibriums, create tensions, and change system needs. The system then adjusts through changes in the Goalattainment and Adaptation-functions and settles down in a new equilibrium. For deliberate (purposive) transitions, political leaders

\footnotetext{
7 One of the reviewers suggested that critics often use the label 'functionalist' if they want to discredit an approach.
} 


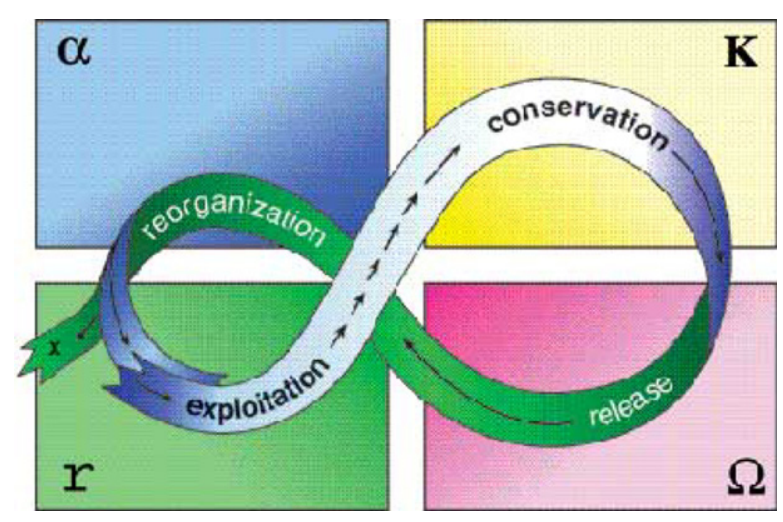

Fig. 2. The adaptive cycle in complex system evolution (Holling, 2001: 394).

and experts develop new goals and subsequently use science and technology to adjust the economic sub-system. The new system is then anchored in new behavioural norms and values through the internally oriented functions (Integration, Latency). Functionalism thus tends to assume a top-down 'cockpit' view with benevolent leaders and experts adjusting systems in appropriate directions (technocracy).

Complex systems theory conceptualizes transitions as punctuated equilibria, shifts from one dynamically stable state to another (Holland, 1995). Holling (2001) schematically portrays an adaptive cycle, which is supposed to hold for all complex adaptive systems and consists of four phases: exploitation/growth, accumulation/conservation, collapse/release and renewal/reorganization (Fig. 2).

In the growth phase, entrepreneurs exploit new opportunities, gradually leading to the emergence of a new system (guided by an attractor). As connections increase and resource accumulate, systems gain stability and move into the conservation phase, characterized by a semi-stable equilibrium that may persist for a long time. When internal dynamics create rigidities (reducing the system's adaptive potential) or vulnerabilities (moving the system towards thresholds), external shocks may lead to system collapse, the release of accumulated resources and a shift towards a new 'basin of attraction'. This short phase is followed by reorganization of elements and resources (self-organization, experimentation, new combinations). The emerging new configuration then provides new opportunities for entrepreneurs.

This abstract representation shows family resemblances to Schumpeterian waves of creative destruction. ${ }^{8}$ But since specific social mechanisms remain underspecified, it also has deterministic and teleological overtones (related to attractors and predetermined phases).

\subsubsection{Sustainability transitions}

For sustainability transitions, structural-functionalism argues that societies, especially policy makers, should set overarching environmental goals (e.g. the Kyoto Protocol, Millennium Development Goals). The translation of goals into policy instruments can be difficult, however, if the environmental problems do not (yet) hinder the immediate functioning of existing systems. The environmental sense of urgency will then be lower than for functional problems such as congestion or energy security that directly affect transport and energy systems. In a functionalist logic (external)

\footnotetext{
${ }^{8}$ An important difference, however, is that entrepreneurial action and the emergence of novelties typically precede, and actually contribute to, system collapse in evolutionary economics. Hollings sequential phases may thus not hold in the social domain where actors have foresight and imagination.
}

environmental shocks and disasters may therefore be needed to achieve sustainability transitions.

Acknowledging non-linear dynamics and uncertainties in complex systems, scholars in the Resilience Alliance (www.resalliance.org/1.php) argue for adaptive management of socio-environmental systems based on diversity, learning, flexibility, stakeholder involvement (Berkes et al., 2003). This work focuses more on adaptation than mitigation, asking how socioenvironmental systems should adapt to stresses that come from natural resource exploitation or environmental change. Although the purpose is to prevent transitions (understood as collapse of productive eco-systems), it is interesting that these suggestions have similarities with transition management (Rotmans et al., 2001) that aims to stimulate transitions to more sustainable systems.

\subsection{Conflict and power struggle}

\subsubsection{Causal agents, causal mechanisms, exemplars}

Causal agents in the conflict and power ontology are collective actors (classes, industry associations, social movements, special-interest groups) with conflicting goals and interests. The core mechanism is conflict and power struggle, with dominant groups using power (force, domination, control, exclusion) to protect their interests against subordinate groups that seek change.

Conflict theories are opposites of functionalism in various respects. Where functionalism sees society as static, conflict theories see processes and struggles; where functionalism emphasizes the orderliness of society, conflict theorists see contestation and conflict; where functionalism sees society as being held together by norms, values and shared goals, conflict scholars argue that order arises from coercion (powerful groups suppressing opponents).

There are various conflict and power theories, which highlight different sources of power and different social groups. Marx, for instance, emphasised the power related to material resources, arguing that capitalists who own property and 'means of production' have control over workers who must sell their labour to earn a living. In response to Marx's presumed economic determinism (with technical and economic 'substructures' driving change in institutional and cultural 'superstructures'), Hegelian Marxists such as Gramsci (1932) argued that stability of the status quo not only comes from economic domination and state coercion, but also from 'hegemony', ideology and belief systems that make existing structures look 'natural' and prevent the emergence of new (class) consciousness. Critical theorists from the Frankfurt school (e.g. Horkheimer and Adorno, 1947) also emphasized the cultural dimensions of power and oppression, in particular the rise of culture industries and instrumental rationality. ${ }^{9}$ While NeoMarxist theories tend to focus on collective actors, other conflict theorists shifted the focus to 'micro-power' (Collins, 1975) and conflicts between self-interested individuals. Struggles, plotting, and coalition building thus appeared as a dimension of all social domains where people have conflicting interests. Labour process theory (Braverman, 1974) showed that the introduction of new technologies in factories, which other theories may perceive as rational choices, contains struggles and conflicts, with managers trying to increase control over workers. In a similar vein, Hård (1993) developed a social conflict approach that criticized the Social Construction of Technology Approach for analyzing interpretive closure processes in terms of consensual negotiation and highlighted power struggles as closure mechanism in technological

\footnotetext{
${ }^{9}$ Foucault also developed views on power in which discourse (or episteme) exerts influence by defining what is acceptable (Foucault, 1970).
} 
change. Conflict and power scholars have thus made crossovers to other ontologies.

\subsubsection{Transition dynamics}

Transitions do not occur when incumbent actors are strong enough to marginalize, ignore or oppress challengers. Change thus arises from shifts in the balance of power, which allow challengers to push through transformations of existing structures (accommodation of new demands) or overthrow incumbents ('revolution').

Policy frameworks (regulations, taxes, policy programmes) that influence economic frame conditions form an important dimension for struggle and conflict in socio-technical transitions. Incumbent regimes are often stabilized by corporatist networks with mutual dependencies between industry and policy makers (Meadowcroft, 2005). Because governments depend on industries to provide employment and economic growth, they often provide favourable conditions and protection. Niche actors, who also lobby for subsidies or favourable regulations, are usually less influential, because they have less political and economic clout. Change then becomes more likely if the economic growth of niches increases their political strength and bargaining power. Corporatist networks may also change because of credibility pressure from public opinion (see the discussion under structuralism) and the electorate, the other constituency policy makers depend on.

\subsubsection{Sustainability transitions}

The problem for sustainability transitions is that many unsustainable industries have many economic resources and good political contacts, which may hinder, delay or water down strict environmental regulations. Regarding European oil, coal and automobile industries, Levy and Newell (2000: 13-14) found that "business interests have significant scope to define the policy agenda. (...) European business tends to enjoy good relations with the most influential government departments or directorate generals. (...) The European Roundtable of Industrialists, made up of chief executive officers from 45 leading European companies is arguably one of the most influential interest groups in Brussels" (p. 14). Sustainability transitions in this ontology may thus require either increasing pressure from public opinion on policy makers or further growth of 'green' niches into important economic sectors that can successfully lobby for further regulatory changes.

\subsection{Relationism (interactionism)}

\subsubsection{Causal agents, causal mechanisms, exemplars}

Relationism is a non-essentialist process ontology, which criticizes other ontologies for assuming that people have foundational attributes and for (fruitlessly) searching for ultimate causes. Relationism instead assumes that the identity, preferences and interests of individual actors are fluid and constituted by relations and ongoing interactions, which are therefore the causal agent. Dynamic networks are primary, actors secondary. ${ }^{10}$

"In this point of view, which I shall label 'relational', the very terms or units involved in a transaction derive their meaning, significance, and identity from the (changing) functional roles they play within that transaction. The latter, seen as a dynamic unfolding process, becomes the primary unit of analysis rather than the constituent elements themselves" (Emirbayer, 1997: 287).

"In short, the actor's ontology is variable: his or her objectives, interests, will and thus identity are caught up in a process of

\footnotetext{
10 This differ from social network theories that start with individual actors who subsequently build networks to further their interests.
}

continual reconfiguration, a process that is intimately related to the constant reconfiguration of the network of interactions in which he or she is involved" (Callon, 1998: 252-253).

Causal mechanisms emphasise processes such as alignment, enrolment, attachments, translation, co-construction and mutual constitution. One exemplar is figuration sociology (Elias, 1978), which argues that actors are caught up in social figurations characterized by emergent characteristics and unintended consequences:

"A game process, which comes about entirely as a result of the interweaving of the individual moves of many players, takes a course which none of the individual players has planned, determined, or anticipated" (Elias, 1978: 95; italics in original).

While moves by individual actors and specific events can be explained with causal mechanisms (e.g. calculation, power struggles, interpretation), the interweaving of individual moves leads to event sequences and aggregated processes that are not foreseen or controlled.

An exemplar in the STI-field is actor-network theory (e.g. Latour, 1987). While Elias looks at social figurations, ANT develops a relationist view that includes materiality (artefacts, technology). In this view, humans not only shape artefacts, but artefacts also shape humans. ANT therefore talks of human and non-human 'actants' and conceptualizes innovation as complex alignment process of heterogeneous elements. Practice theories form another exemplar, focusing on local practices and everyday lifeworlds, and highlighting mechanisms such as improvisation, tinkering, bricolage, and repair work (see also Shove and Walker in this special issue).

"A practice approach should bring forth the technician as tinkerer (following the 'logic of practice') rather than the engineer as theoretician, and technology as bricolage (informed by 'practical sense') rather than engineering as knowledge production" (Hård, 1994: 574; italics in original).

Practice theories are "opposed to universalizing models and stress the cultural contingency and historicity. (...) For practice theory, only the new focus on the groundedness of human action in bodily routines and in practical understanding is suitable to remain aloof from modernist models of the social and the agent" (Reckwitz, 2002: 261). Practice approaches have also been extended to user practices, which are conceptualized as fluid constellations of material objects/technologies, symbolic meanings and images, and user competence/skills (Shove and Pantzar, 2005).

While relationism criticizes other ontologies for reification and essentialism, other ontologies criticize relationism for relativism and limited explanatory potential. Relationist theories contain no exogenous causes, because everything is endogenized in terms of networks and ongoing relations. ANT, for example, conceptualises the world as 'flat' (or folded) and refutes the notion of institutions or structural levels:

"So you are freed from this image of a multi-level society. You don't need several layers, different layers. You don't need infrastructure and superstructure and embeddedness. You only need places that are connected and the possibility of actors and information to circulate from one place to another one." (Callon, 2002: 293).

\subsubsection{Transition dynamics}

The relevance of relationist and practice theories for large-scale transitions is unclear for three reasons. First, these theories typically focus on local practices and projects, e.g. a French electric vehicle development project (Callon, 1980) or a Parisian public transport project (Latour, 1996). While it is doable to empirically 'follow the actors' in these projects, this method creates practical 
problems for large-scale transitions with many thousands of actors. The second problem is that the focus on local practices, fluidity and contingency makes it difficult to distinguish more generic patterns that span various practices. ${ }^{11}$ Third, these theories practice a scientific style that is less focused on developing analytical models and more on criticizing conventional notions and assumptions to make room for new vocabularies. Law (1999: 3), for instance, praises ANT for its "shock value" and "potential for scandal", because "sacred divisions and distinctions have been tossed in the flames." Theories may therefore be defamiliarizing and rich in paradox. The new vocabulairies and concepts can, however, be criticized for empiricism: good at description, weak at explanation (Collins and Yearley, 1992). In response, ANT-scholars criticised the distinction, arguing that "A complete description of network dynamics might provide a better explanation, in the end, than the delusive search for causes" (Callon and Latour, 1992: 362). Because relationism and practice theories tend to refrain from developing analytical models, it is difficult to generalize how they understand the dynamics of transitions.

\subsubsection{Sustainability transitions}

Some practice theorists have shifted the attention in environmental debates to transitions in user practices and everyday life (Shove, 2003; see also Shove and Walker in this special issue). In the last 50-100 years, people experienced and enacted major shifts in social practices such as bathing and showering, office heating and cooling, and the laundry, leading to major increases in the use of chemicals, water, and energy (Shove, 2003). Also Røpke (2001) argues that the environmental debate is skewed towards supplyside issues, ignoring major (unsustainable) demand-side changes that led to larger housing areas, more household equipment, higher meat consumption, greater mobility, more long-distance travel, etc. These scholars therefore ask for more analytical attention to the 'socio' in socio-technical transitions and for analysis of the construction of 'normality' in user practices. Shove's practice approach (2003), for instance, aims to understand "the transformation of ordinary routines and habits (...) how meanings, practices and technologies hold together and how integrative processes themselves influence the rate and direction of change" (p. 20). It is difficult to generalize beyond the case studies, however, because her practice approach "does not generate one all-encompassing theoretical model" (p. 20) and should be seen as "a different way of thinking" (p. 20). Shove and Walker repeat the same message in this special issue. Their commentary suggests that changes in social practices come about through integration (or erosion) of various 'elements' or 'ingredients'. ${ }^{12}$ They use terms such as 'horizontal circulation', 'interconnectedness of many elements', 'active integration of constitutive elements', and 'practices have emergent and uncontrollable trajectories' to hint at interesting dynamics. But because these terms are more descriptive than explanatory, it remains unclear how they can be used to 'analyse the dynamics of convention' in a way that goes beyond the empirical mapping of individual cases.

\subsection{Intermediate conclusion}

The previous sections demonstrated the breath of generic social science traditions and how their insights can be related to sociotechnical transitions and sustainability. Shove and Walker (2007)

\footnotetext{
11 This is related to the analytical fear for reification (something that Willem Halfman once called 'reificifobia'), which leads to limited attention for broader structures (cognitive, political, economic) that could be useful for explaining broader patterns.

12 These elements remain under-defined, however, and are introduced via examples rather than via conceptual arguments.
}

were therefore right in calling for "exploring other social scientific, but also systemic theories of change". But the discussion also showed that most ontologies focus on particular aspects of socio-technical transitions, addressing particular dimensions of this multi-faceted phenomenon. Furthermore, some ontologies appear to have a default orientation towards stability, equilibrium or incremental change, especially rational choice, structuralism and functionalism. It is therefore more difficult for these ontologies to explain socio-technical transitions and discontinuous change. Their explanations typically rely on an external impulse or shock. The other ontologies have a more intrinsic orientation towards change, which also makes their explanation of transitions more endogenous. For relationism, however, its explanation of transitions remains unclear, as indicated in Section 2.7. Table 2 summarises the differences between the ontologies on both dimensions (default orientation to change, explanation of transitions). Section 3 further discusses the implications of these differences for relations to the MLP.

\section{Different ontologies and the MLP}

How does the MLP relate to different ontologies? Do (some of the) ontologies suggest directions for further conceptual elaboration of the MLP? Before addressing these questions, I distinguish four meta-theoretical positions with regard to inter-ontology relations, and link the MLP to one of them.

\subsection{Four meta-theoretical positions}

The previously discussed ontologies refer to foundational positions and assumptions about the properties of causal agents and causal mechanisms in the social world. Specific theories and conceptual frameworks may stay within one ontology, as the previously discussed exemplars, or work from multi-dimensional and more complex assumptions. Regarding this issue, I distinguish four meta-theoretical positions: (1) Complete integration: theories combine all (or many) ontologies into an encompassing synthesis, (2) Incommensurability: theories should work within one ontology; combination is not possible, because foundational assumptions differ too much (cannot be 'measured' in the same units), (3) Eclecticism: theories pragmatically combine bits and pieces from different ontologies without much concern for differences in foundational assumptions, (4) Inter-ontology crossovers: theories aim for interplay, not synthesis, between a few ontologies; crossovers may be possible when ontological assumptions are not too different.

The first position, full integration into an encompassing theory, is difficult, because some ontologies focus on individual actors, others on larger wholes and collectives; some focus on 'objective' reality and material interests, while others see reality as inter-subjectively created. Attempts at integration (e.g. Bourdieu, Alexander) have been criticised for abstract theorising about philosophical principles rather than sociological mechanisms, for coining new words that restate foundational tensions without solving them, and for a general dissociation from empirical research (Burger, 1986; Van den Berg, 1998). Secondly, full integration is difficult because ontologies are associated with different epistemological (and methodological) styles (DiMaggio, 1995), e.g. (a) 'theory as covering laws', where explanations derive from drawing on general laws; the methodological emphasis is on measurement, variables, and statistical generalization; (b) 'theory as narrative', which explains social processes as sequences of events that are enacted by social groups; the methodological emphasis is on intentions and motivations (hermeneutics, Verstehen), analytical generalization, and dynamic patterns (c) 'theory as enlightenment', which aims to clear away conventional notions, uncover hidden 
Table 2

Characteristics of transitions in different ontologies.

\begin{tabular}{|c|c|c|}
\hline & Default orientation: change or stability & Explanation of transitions \\
\hline Rational choice & Stability (equilibrium) or incremental change & $\begin{array}{l}\text { Difficult. Requires exogenous impulse (price changes) followed by } \\
\text { gradual adjustment (of resource allocation) }\end{array}$ \\
\hline Evolution & $\begin{array}{l}\text { Dynamic stability (incremental change along lineages) and } \\
\text { radical change (speciation, niches, competition) }\end{array}$ & $\begin{array}{l}\text { Endogenous change (radical innovations) and/or exogenous } \\
\text { changes in selection pressures }\end{array}$ \\
\hline Structuralism & Stability & $\begin{array}{l}\text { Difficult. Changing ideologies and belief systems often remain } \\
\text { exogenous }\end{array}$ \\
\hline Interpretivism/constructivism & Ongoing change and sense-making & $\begin{array}{l}\text { Radical change through endogenous second-order learning } \\
\text { processes (change in cognitive frames) }\end{array}$ \\
\hline Functionalism (systems theory) & Stability (system equilibrium) & $\begin{array}{l}\text { Difficult. Requires exogenous shocks, followed by gradual } \\
\text { adjustments }^{\mathrm{a}}\end{array}$ \\
\hline Conflict and power struggle & $\begin{array}{l}\text { Stability (powerful actors suppress change), incremental } \\
\text { change ('reform' to accommodate protests) and radical } \\
\text { change ('overthrow' by challengers) }\end{array}$ & Endogenous struggles between incumbents and challengers \\
\hline Relationism & Continuous process (change or reproduction) & $\begin{array}{l}\text { Unclear. No distinction between radical or incremental change. } \\
\text { Focus on micro-processes and local projects }\end{array}$ \\
\hline
\end{tabular}

a Complex systems theory does acknowledge that endogenous processes may create 'conditions for change' in which external shocks can have big effects.

structures, or introduce unconventional, creative and surprising frameworks.

The second position, incommensurability, assumes that interaction between ontologies is impossible. It thus privileges 'normal science' that stays within existing paradigms and hinders theoretical innovations through 'new combinations' between ontologies. It also tends towards reductionism (emphasising single causes) and constant-cause explanations (assuming that one causal mechanism operates continuously and with equal force throughout a process), which are problematic for heterogeneous topics such as socio-technical transitions.

The third position, eclecticism, can produce workable frameworks for particular purposes (like good engineers can sometimes combine technical elements without caring too much about the underlying scientific foundations). The risk, however, is that ad-hoc combinations produce inconsistent frameworks and remain fuzzy about dynamic relationships between very different dimensions.

The fourth position, inter-ontology crossovers, focuses on interactions between ontologies (Gioia and Pitre, 1990; Lewis and Grimes, 1999). Crossover approaches recognize differences between ontologies, but work on dynamic interplay rather than overarching synthesis. Ontologies are not perceived as pieces in a jigsaw puzzle, but also not accepted as fully incommensurable. Instead, this position is interested in middle range theories and dynamic mechanisms that form bridges between foundational oppositions. Scholars in this position therefore highlight pluralism, paradox, tensions and recursive mechanisms that go back and forth between seeming opposites (Poole and Van de Ven, 1989; Eisenhardt, 2000). This has resulted in crossover approaches such as actor-centred institutionalism, economic sociology, and institutional entrepreneurship that capture dynamic relations between agency and structure, change and stability, material interests and symbolic meaning, rational strategy and institutional embeddedness. For multi-dimensional phenomena such as socio-technical transitions, the fourth position is particularly fruitful.

With regard to crossovers, I take inspiration from Poole and Van de Ven (1989) who suggest four ways of dealing with alternative or opposing theories. The first way is opposition: "a great deal can be learned from juxtaposing contradictory propositions and assumptions, even if they are incompatible" (p. 566). Although this method assumes the incommensurability position, Lewis and Grimes (1999) suggest it can be employed fruitfully, either through a multi-paradigm review, which theoretically juxtaposes different ontologies, or through multi-paradigm research, which applies divergent ontological lenses empirically and shows the strengths/weaknesses of different ontologies in explaining a concrete case (see Geels, 2009, for an application to pig farming). The second way is spatial separation, which relates different theories by "clarifying levels of reference and the connections among them" ( $p$. 566). This method assumes that one theory operates at one level of analysis, while another operates at a different level. The third way is temporal separation, which takes time into account. In this approach one theory is assumed to hold during one time period (e.g. early phases when things are fluid) and another during another time period (e.g. later phases when things have stabilized). The fourth way is synthesis, for instance by introducing new concepts or perspectives that show that opposing theories are two sides of the same coin.

Section 2 applied Poole and Van de Ven's first way, juxtaposing different ontologies. The sections below apply their second and third way, discussing if and how various ontologies can be related to levels or time periods in the MLP. First, however, I discuss the main ontologies that underlie the MLP, namely a crossover between evolution theory and interpretivism/constructivism.

\subsection{The main crossover in the MLP: evolution theory and interpretivism}

The MLP originates from the Twente school's quasi-evolutionary theory (Rip, 1992; Schot, 1992; Rip and Kemp, 1998) that aimed to make evolutionary variation-selection-retention mechanisms more sociological via crossovers with interpretivism/constructivism (mainly from STS). ${ }^{13}$ Variation is seen as guided by expectations (Van Lente, 1993), visions and beliefs that provide cognitive substance to search and innovation processes by intentional actors. Selection occurs in a multi-dimensional selection environment, which incorporates not only markets and regulations, but also social, cultural, and political requirements. Retention occurs in technological regimes, which are conceptualized as 'rules' rather than routines (Rip and Kemp, 1998). Actors are not cultural dopes who passively follow rules. Instead, they are knowledgeable agents (Giddens, 1984), who interpret and apply rules creatively (although within constraints). Retention is not only a process of 'retaining what works' (as in behavioural theory), but also an interpretive, negotiated and contested process of institutionalization.

This crossover is facilitated by similarities in ontological assumptions. Most importantly, both ontologies assume creative and heterogeneous actors, but also acknowledge the embedded-

\footnotetext{
13 Whereas Genus and Coles's (2008) suggest that SCOT (Social Construction of Technology) should be incorporated in the MLP, interpretivist theories have thus always been part of the MLP.
} 
ness of actors in regimes. Furthermore, both have an intrinsic focus on process and development over time, and can explain both incremental and radical change (Table 2 ).

The crossover allows the MLP to combine the evolutionary interest in long-term patterns (trajectories, speciation, invasion, extinction) with an interpretive interest in social enactment, sensemaking, and cognitive learning. The trajectories and lineages within the levels result from social (inter)actions within semi-coherent rule structures that are recursively reproduced and incrementally adjusted by interpretive actors (Geels, 2004). This accommodates both behavioural learning ('trial-and-error' dynamics from evolution theory) and cognitive learning (sense-making from interpretivism). Between the levels there is an evolutionary logic, with heterogeneous niche-innovations providing (radical) variety that interacts with broader selection environments (at regime and landscape levels). But the creation of fit between variations and selection environments is also seen as an enacted and multidimensional process that not only involves markets, but also social, political and cultural dimensions.

Although the multi-dimensionality of niche-regime-landscape interactions is a strength of the MLP, this is conceptualized in a general and heuristic sense. The MLP could therefore benefit from conceptual extensions of multi-level interaction on various dimensions. Regarding this issue, Section 3.3 therefore explores possible crossovers to the other ontologies.

Regarding the issue of niche-regime interaction, I would first like to suggest, however, that the MLP could benefit from stronger incorporation of business dynamics from evolutionary and cognitive/interpretive streams in strategic management. An empirical consideration behind this suggestion is that the reorientation of incumbent firms will be important for the acceleration and upswing of sustainability transitions. The reason is that incumbent firms in the car, electricity, and food industries posses many complementary assets (see Section 2.1) that are relevant for the upscaling and commercialization of green niche-innovations. Their involvement and serious commitment would thus speed up the breakthrough of 'green' novelties. But such strategic reorientation is unlikely until existing regimes begin to destabilize.

To address this kind of niche-regime interaction theoretically, the MLP might benefit from incorporating the work on dynamic capabilities (Teece et al., 1997), which studies how top managers change and reconfigure existing competencies, and the work on 'ambidextrous organizations' (Tushman and O'Reilly, 1996), which investigates how firms balance the exploitation of existing technologies and the exploration of new ones. This work not only shows that incumbent firms can overcome the lock-in mechanisms that tie them to existing technological regimes, but also suggest that deliberate changes in firm strategy are crucial for reorientation. Levinthal (1992) suggests that the development of new knowledge and competences usually precedes such changes in strategy and mission, because this provides the internal resources for reorientation. Interpretive strategy scholars further argue that strategic reorientation also tends to be preceded by changes in belief systems and interpretive schemes, which alter the perceptions of the future viability of existing regimes and the chances of niche-innovations (Grinyer and McKiernan, 1990; Barr et al., 1992). These kinds of crossovers, which address the co-evolution of firm strategy, perceptions and technological knowledge, can enrich the MLP with business-related mechanisms of niche-regime interactions.

\subsection{Crossovers to other ontologies (or not) and possible extensions of the MLP}

\subsubsection{Rational choice}

In terms of basic assumptions, the conception of agency in the MLP (rule/routine-based) differs from the atomistic and calculat- ing view in rational choice. But the MLP's embeddedness view does not necessarily deny the possibility of 'rational choice'. Instead, rational choice can be a special case in the context of stable rule structures that enable calculation. "In 'hot' situations, everything becomes controversial. (...) In 'cold' situations, on the other hand, (...) the possible world states are already known or easy to identify: calculated decisions can be taken" (Callon, 1998: 261).

Using the punctuated equilibrium framework, we can say that rational choice may hold for periods of incremental change when socio-institutional structures form stable backgrounds that allow rational calculation (Fig. 3). But it faces problems for periods of ferment, when background structures are opened up and social, political and organizational processes gain prominence. The accompanying flux, uncertainty and fluidity complicate cost-benefit calculations in those periods.

Although rational choice has limited relevance for understanding transitions (eras of ferment), the MLP could accommodate rational choice at the regime level during stable periods. Rational choice may also offer insights for the diffusion phases of new technologies: once dominant designs and new institutions have stabilized, policy makers and firms are better able to make costbenefit calculations to underpin large-scale investment decisions. But since both aspects can also be explained by evolutionary economics, the MLP does not really need rational choice. Furthermore, rational choice offers few insights into niche-regime interactions. I therefore suggest that crossovers to rational choice do not form an important research agenda.

\subsubsection{Structuralism}

The MLP already makes ad-hoc crossovers to structuralism, incorporating macro-cultural changes at the landscape level. But this kind of 'top-down' structuralism has been criticised for reification, a monolithic view of cultural deep structures, and determinism. Cultural sociology and discourse analysis therefore developed more dynamic and agency-oriented approaches that conceptualize linkages between symbolic deep structures on the one hand and framing struggles and 'collective meaning making' on the other hand (Spillman, 2002). These approaches suggest possibilities for theoretical extensions of the MLP that address cultural interactions between niche, regime and landscape levels.

The 'interpretive turn' in cultural studies argues that meaning arises from interpretation, a process in which actors actively draw upon cultural deep structures. Meaning arises from the mobilization and ordering of cultural symbols and cognitive categories. Cultural deep structures thus become 'toolkits' or 'repertoires' that actors use to make sense (Swidler, 1986). Discourse analysts added interactive dimensions by addressing collective sensemaking around specific issues. Because collective sense-making is an ongoing process, the interpretations sediment into particular discourses, i.e. ways of talking and thinking about issues (Hajer, 1995). Discourses contain deep structural elements that are framed by actors in particular ways. This discursive framing is a contested process in which social movements, industry associations, policy makers and other special-interest groups struggle to shape discourses to their advantage. The discursive struggle between different 'discourse coalitions' (Hajer, 1995) is played out on public stages (public debates, media, newspapers) for particular audiences (the wider public, policy makers or venture capitalists). The various actors engage in discursive struggles because discourses influence how relevant audiences think and talk about particular issues (e.g. the causes and urgency of social problems, the potential and desirability of technologies), which affects their cultural legitimacy, which in turn influences public support, political protection or financial resources (Suchman, 1995; Lounsbury and Glynn, 2001). Discursive action and legitimacy thus form mechanisms that link cultural dimensions to politics and economics. 


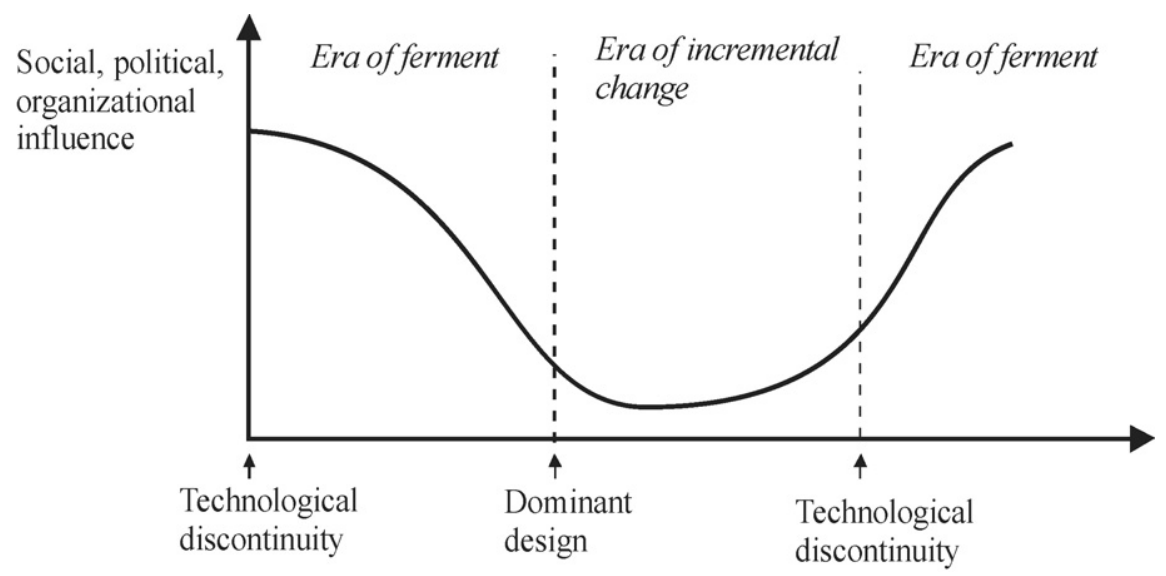

Fig. 3. Degrees of social shaping during transitions and stable periods (Tushman and Rosenkopf, 1992: 339).

These crossover mechanisms also provide interesting extensions of the MLP (Geels and Verhees, 2008). While the MLP's landscape level refers to the deep structural dimension of culture, actors at regime and niche levels engage in cultural actions, developing discourses that draw on deep cultural categories and frame issues in such a way as to confer legitimacy to their actions and/or technologies. Regime actors develop discourses that maintain or restore legitimacy when they are faced with problems or criticisms (television debates, advertisements). Social movements and niche actors try to delegimate the regime by framing industry practices or responses to problems as 'insufficient', 'outdated', 'irresponsible', or 'unacceptable' (Oliver, 1992). Niche actors also engage in cultural framing actions to enhance the legitimacy of niche-innovations, which initially suffer from the liability of newness (Freeman et al., 1983) and have low legitimacy because they are perceived as 'strange', 'inappropriate' or 'out of place'. To enhance their legitimacy, niche actors develop positive discourses with promises and enticing visions of particular innovations (Van Lente, 1993). Opponents of niche-innovations, on the other hand, may develop storylines that downplay the relevance of these innovations or highlight possible disadvantages and risks.

These kinds of crossovers to structuralism may enrich the MLP with cultural mechanisms that enable scholars to analyze how discursive struggles between niche and regime actors, in the context of changing (landscape) repertoires, influence the speed and direction of socio-technical transitions (Geels and Verhees, 2008).

\subsubsection{Functionalism}

The MLP has been criticized for being functionalist (Smith et al., 2005; Genus and Coles, 2008), although more via labelling than substantiated argument (see also footnote 7). This criticism is perhaps a reflex to the conceptualization of socio-technical systems as fulfilling societal functions. There may indeed be traces of neofunctionalism in the MLP, in the sense that persistent functional problems or tensions in transport, energy, and food systems are seen as one of the drivers for transitions if perceived by actors and placed on relevant agendas. But the MLP is not a functionalist framework because it does not assume that all actors work towards shared system goals, has no teleology, and no bias towards stability. Coordinating regime rules are described as semi-coherent, which allows for possible tensions and conflicts. Furthermore, it is useful to differentiate between the general societal functions such as transport, energy, food, entertainment, communication and specific functional attributes such as speed, safety, comfort, fuel use, $\mathrm{CO}_{2}$ emissions, land use, noise, landscape influence, and public investment in the case of transport. While the MLP accepts the existence of general societal functions, it acknowledges heterogeneity in specific func- tional attributes with different social groups ranking and appraising these attributes differently. Interpretations, negotiations and struggles over these attributes actually help explain specific differences between socio-technical systems in various countries. I therefore argue that the MLP does not make crossovers to functionalism.

Additionally, functionalism makes it difficult to investigate interactions between niches and regimes, which are crucial in the MLP. The reason is that functionalism and complex systems theory focus on existing systems (such as eco-systems, bird swarms, stock markets) and their adaptation to external stresses or shocks. It does not focus on niches where radical innovations actually emerge in relative separation from the system. Within system theory frameworks it is therefore difficult to investigate interactions between niches and regimes. I therefore suggest that complex systems theory constitutes an alternative way of investigating transitions, with intriguing similarities but also differences to the MLP (see Sections 2.5.2 and 2.5.3).

\subsubsection{Conflict and power}

The MLP already makes crossovers to the conflict ontology, because power and politics form an important dimension of selection environments that usually stabilize existing regimes (through corporatist networks and favourable regulations) and hinder the breakthrough of niche-innovations. But this is mostly done in an adhoc way. Because the MLP does not provide detailed explanations of the sources and changes of power, it could benefit from richer, multi-faceted views of power and conflict (Smith et al., 2005). Lukes (1974), for instance, distinguished 'three faces of power', the first being the use of political power and authority in formal decisionmaking arenas. The second relates to the power to place issues on or keep them off the agenda (backroom deals, lobbying, implicit threats). The third is about influencing the preferences of subordinate groups so that they do not feel the urge to place issues on the agenda. This forms the ideological dimension of power highlighted by Hegelian Marxists, critical theorists and Foucault.

The MLP may also benefit from crossovers to social movement theory (SMT), which explicitly deals with conflicts between established orders and groups that aim to correct some perceived injustice. These crossovers may be especially fruitful for transitions towards normative goals (such as 'sustainability'). Because social movements start as outsiders to existing orders, they tend to use non-institutionalized action (protest marches, blockades, strikes, petitions) to exert pressure for change. Early SMT scholars highlighted the mobilization of resources (members, money, expertise) as the main mechanism for increasing the pressure (McCarthy and Zald, 1977). To complement this 'internal push' mechanism, other scholars (e.g. Kitschelt, 1986) demonstrated that the influence of 
social movements is also related to political opportunity structures (e.g. the strength of the state vis-à-vis civil society, formal regulations, and the role of the judiciary). The third mechanism for exerting influence is cultural framing, because this defines the cognitive space in which struggles are played out (Eyerman and Jamison, 1991). Social movements can contest the dominant ideology and develop alternative discourses that influence public opinion and create legitimacy pressures on policy makers (Benford and Snow, 2000). While SMT often highlights political contestation, technology-oriented scholars also drew attention to the constructive role of social movements in nurturing niche-innovations when they have low legitimacy (Hess, 2005; Smith, 2005). SMT thus provides a multi-dimensional view on power struggles where social movements contest existing regimes and support niches.

\subsubsection{Relationism}

The MLP has been inspired by relationism, e.g. via Rip and Kemp (1998) who draw on actor-network theory (ANT) notions such as heterogeneous configuration, a socio-technical focus where social and technical elements co-construct each other, and an emphasis on ongoing processes, linkages and alignments. Also some of Geels and Schot's (2007) transition pathways (reconfiguration and dealignment/realigmment) build on these kinds of dynamic notions.

Despite these inspirations, scholars working on the MLP have not actively pursued further crossovers with ANT. The main reason is that ANT has a flat (or folded) ontology, which denies the analytical usefulness of 'levels'. Within ANT it is therefore difficult to investigate multi-level relations between niche-innovations, regimes and landscapes. ${ }^{14}$ One might argue that ANT could be positioned at the MLP's niche-level. ANT's emphasis on innovations 'in-the-making' and the focus on what actors do in practices to make heterogeneous configurations work has some fit with the fluidity, uncertainty and experimental projects within technological niches. But ANT-scholars might perceive such an argument as pushing their views into an analytical straightjacket. Their view on coordination (which arises from transactions and circulations between local practices), for instance, might sit uncomfortably with the MLP's view on coordination via rules, routines and structures. For the topic of socio-technical transitions, the problem with ANT is that its focus on innovations 'in-the-making' precludes attention to what happens with innovations when they are made and have stabilized. Van Lente (1993: 31) summarises this problem as follows:

"Their limitation is that the analysis terminates as soon as a regularity or pattern is established. Authors explain the outcomes of interactions or translations, but forget that as soon as these outcomes are produced, they continue to exist. Their analyses tend to stop as soon as an artefact, an organization or other socio-technical outcome starts to have a 'life of its own"'.

ANT thus pays less attention to the diffusion of technologies, their sedimentation into background structures and the emergence of stable patterns. Because ANT focuses on what actors do, it gives less attention to the sedimented patterns in which they are embedded and the structures that actors take for granted (e.g. rules and routines). This criticism applies less to other relationist approaches such as practice theories, in particular Shove's work on consumer practices that analyses how existing routines, meanings and technologies influence activities in 'everyday life'.

The micro-focus, flat ontology and complexifying epistemology (with suspicions towards analytical models) clearly complicate

\footnotetext{
${ }^{14}$ Genus and Coles (2008) seem unaware of this problem when they suggest that actor-network theory should be integrated in the MLP.
}

crossovers of relationism with the MLP. ${ }^{15}$ Nevertheless, ANT does have notions of networks with varying degrees of stability. Callon et al. (1992), for instance, suggests that techno-economic networks are more stable if they are longer, more complete/chained and convergent. This view creates opportunities for investigating interactions between stable networks (e.g. existing socio-technical systems) and emerging networks (e.g. niche-innovations). Despite initial suggestions to develop such an "actor-network theory at a meso-level" (Geels, 2006: 450), much conceptual work remains to be done to develop such a model. ${ }^{16}$ While crossovers to the MLP may be possible, relationism forms an intriguing ontology by itself that can perhaps develop alternative ways of investigating transitions.

\section{Concluding remarks}

The foundational reflections in this article have clarified the theoretical roots and assumptions of agency embedded in the MLP and produced directions for further theoretical extension. The article also provides a multi-disciplinary map for a broader and more reflexive study of socio-technical transitions. Such a broad map is particularly relevant for future sustainability transitions, which have three additional complexities compared to many historical transitions. First, sustainability is a normative goal and a collective good problem (with associated prisoner dilemmas and free rider problems). The former means that sustainability transitions will be full of debates about the relative importance of various environmental problems, which entail deep-seated values and beliefs. The latter means that private actors have no immediate incentive to address sustainability problems. Public authorities and civil society will therefore be crucial drivers for sustainability transitions. Their actions will need to change economic frame conditions and/or consumer practices, which subsequently incentivize private actors to reorient their innovation and commercial activities.

Second, current transport, energy, agri-food and other domains are characterized by multiple 'green' niche-innovations. This variety deviates from many historical transitions that were characterized by one, two or sometimes three niche alternatives. It also raises difficult questions of directionality and choice between multiple transition pathways, especially since these will influence our future ways of life. One set of questions is how to assess and appraise the costs, benefits, and negative side-effects of various 'green' pathways? Such assessments not only entail incompatible criteria (e.g. the landscape influence of many wind turbines versus risks of nuclear energy), but also values which differ for various groups. Another set of questions is who makes the choices? Should this be done by governments, backed up by various experts, committees and technical calculations? Or should this be a more inclusive and participatory process, with broader stakeholders, societal groups and publics? The answer partly depends on one's view of sus-

\footnotetext{
15 Rammert's (1997) techno-structuration approach is promising in this respect, because it explores crossovers between constructivism, evolution theory and structuration theory. Using the analytical notion of local level (innovative projects) and global level (technological field), Rammert suggests a rethinking of technology studies that is: "Inspired by Giddens's new rules of sociological method, a constructivist explanation of technology's generation on the local level is combined with a social evolutionary approach of structural selection on the global level" (p. 171).

16 Also Shove's practice theory may be less incompatible with the multi-level perspective than she suggests. Although Shove and Walker (this special issue) argue for a 'flatter model characterised by multiple relations (rather than hierarchical levels)', they also use notions such as 'enduring and relatively stable practices' and 'trajectories' (which refer to relatively stable and predictable structures). So, even within their practice approach it is possible to investigate relations between emerging fluid structures (such as London's congestion charging) and existing stable structures. In that sense, there may be similarities with the MLP that could be further explored (rather than rejected outright).
} 
tainability transitions. If these are seen as a technical challenge of developing and installing 'green' innovations, one may tend to the former answer. If these are seen as a broad social transformation process that also entails consumer behaviour and lifestyles, one may tend towards the latter. In both cases, however, legitimacy and public support will be important with regard to substantial financial investments and 'policies that bite' (e.g. higher taxes, stricter regulations). Narratives and discourses will therefore have to accompany investments, innovations and policies.

Third, many of the new environmental problems (e.g. climate change, biodiversity, resource depletion) are global, not directly visible or tangible, and are mainly about the future. They therefore differ from other environmental problems (such as water pollution, smog, and acid rain), which were local, (relatively) immediate, visible and tangible. There were clear problem sufferers who could mobilize against specific problem causers, and ask for compensation or solutions. This is more difficult for the new environmental problems, where cause-effect chains are uncertain, problem causation more diffuse, and problem sufferers either distant in time (future generations) or in space (other countries). The mobilization for these kinds of problems will therefore depend to a large extent on social movements (often supported by concerned scientists) and public opinion. This is an additional reason why discourse, socio-political framing and debate are important in sustainability transitions.

Innovation studies is well placed to address the topic of socio-technical transitions (see also Smith et al. in this special issue). Schumpeter (1934) already characterized innovation as multi-dimensional process involving changes in product, production process, markets, supplies/inputs, and organization. And the innovation systems literature conceptualizes innovation as distributed multi-actor process, paying attention to the co-evolution of technology, social networks and institutions. Innovation studies' insights about the interactions between businesses, universities, governments, and markets/consumers remain important for the study of socio-technical transitions. But to address the analytical challenges around normativity, directionality, and social mobilization, innovation studies may need to broaden its analytical scope to include additional dynamics related to civil society, social movements and consumer behavior. Further crossovers to cultural studies, political economy, economic sociology and consumer studies may therefore be fruitful for a comprehensive study of socio-technical transitions to sustainability. One caveat to this call for opening up innovation studies is that various theories cannot be added up and combined as pieces in a puzzle. One needs to be reflexive about differences in theoretical traditions and underlying assumptions. In a recent assessment of the STIfield, Morlacchi and Martin (2009) made similar points, firstly arguing that the field faces epistemic challenges because it is an "intrinsically interdisciplinary, problem-oriented and pluralistic field" (p. 579), and secondly calling for "implicit assumptions and social theories need to be made explicit" (p. 579). The ontological discussion in this article has aimed to contribute to this, and make a multi-disciplinary assessment of fruitful crossovers regarding socio-technical transitions. The second caveat is that broader co-evolutionary frameworks should go beyond simple statements of 'seamless webs', 'co-construction', 'complexity' or 'heterogeneity', and delve deeper into the underlying causal mechanisms:

"The challenge for [co-evolutionary] research here is to go to a much finer analysis at both empirical and theoretical levels, and to move from the statement that everything is coevolving with everything else to the identification of what is coevolving with what, how intense is this process and whether indeed there is a bi-direction of causality" (Malerba, 2006: 18).
While the focus on patterns and mechanisms was already present in the MLP, this article aimed to further advance that agenda, by explicating various foundational mechanisms and how they relate (or not) to the MLP. While there are relevant calls to better operationalize the MLP (Genus and Coles, 2008; Markard and Truffer, 2008), I suggest that open frameworks are better suited to take this agenda forward than precise models (see also Smith et al. in this special issue). In that respect, I build on Porter (1991) who distinguished two approaches to theory building, the first being "situation specific but rigorous (read mathematical) models of limited complexity. Each model abstracts the complexity (...) to isolate a few key variables whose interactions are examined in depth" (Porter, 1991: 97). While such rigorous models are possible for demarcated topics that stay within one ontology, they face difficulties with broader, multi-dimensional and complex topics. In the latter case, frameworks or perspectives may be more relevant. "A framework (...) encompasses many variables and seeks to capture much of the complexity (...). Frameworks identify the relevant variables and the questions which the user must answer to order to develop conclusions tailored to particular industry and company. (...) In addition, all the interactions among the variables in the frameworks cannot be rigorously drawn. The frameworks, however, seek to help the analyst to better think through the problem" (Porter, 1991: 98).

Genus and Coles (2008) characterize the MLP as heuristic. While they mean this as criticism, it can also be seen as a compliment in the sense that MLP frames the topic of transitions in a certain way and asks particular questions about patterns and mechanisms. For a new research endeavour this is an important task:

"Problems are more important structurally than solutions, in that they can better muster the energy and interest of a community of intellectuals. This is not a facile paradox, for 'problems' do not present themselves spontaneously; the ability to raise questions already implies a conceptual scheme in which something is defined as an issue. It suggests at least the prerumblings of an emerging intuition of what the shape of that problematic world is like and puts us on a path to sharpening the focus of a full-scale paradigmatic vision" (Collins, 1986: 1346).

The MLP is not a grand theory or unifying framework that synthesizes all available theories, but a middle range theory (Geels, 2007) that addresses a specific topic, is based on particular crossovers between evolution theory and interpretivism, and can perhaps be enriched with further crossovers to power theories and structuralism. But while the MLP is a flexible framework, it cannot (and does not want to) incorporate all social theories. Rational choice, functionalism, and relationism are rich ontologies that can generate alternative frameworks on (sustainability) transitions. Also other permutations and crossovers between social theories can probably generate relevant perspectives. I thus agree with Shove and Walker (2007) that the MLP need not be the 'only model in town'. Transitions to sustainability form a rich and challenging topic that will not only remain socially relevant for decades to come, but may also benefit from dialogues between various approaches.

\section{Acknowledgements}

I want to thank Mike Hobday, Piera Morlacchi, Paul Nightingale, Ed Steinmueller, Andy Stirling, three anonymous reviewers and the special section editors for their thoughtful and stimulating feedback on previous versions of the paper. I am particularly thankful to Johan Schot for our stimulating discussions about ontologies (and other issues) and to the KSI network for providing an intellectually exciting environment. This work has been supported by an ERC grant. 


\section{References}

Alexander, J.C., Colomy, P., 1985. Toward neofunctionalism: Eisenstadt's change theory and symbolic interactionism. Sociological Theory 2, 11-23.

Ansoff, H.I., 1965. Corporate Strategy. McGraw-Hill, New York.

Argyris, C., 1976. Singe-loop and double loop models in research on decision-making. Administrative Science Quarterly 21 (3), 363-375.

Barr, P.S., Stimpert, J.L., Huff, A.S., 1992. Cognitive change, strategic action, and organizational renewal. Strategic Management Journal 13 (Summer special issue), 15-36.

Benford, R.D., Snow, D.A., 2000. Framing processes and social movements: an overview and assessment. Annual Review of Sociology 26, 611-639.

Berger, P.L., Luckman, T., 1967. The Social Construction of Reality: A Treatise in the Sociology of Knowledge. Doubleday Anchor, New York.

Berkes, F., Colding, J.F., Folke, C. (Eds.), 2003. Navigating Nature's Dynamics: Building Resilience for Complexity and Change. Cambridge University Press, Cambridge.

Bijker, W.E., 1995. Of Bicycles, Bakelites and Bulbs: Towards a Theory of Sociotechnical Change. The MIT Press, Cambridge, MA, London, England.

Bos, B., Grin, J., 2008. Doing reflexive modernisation in pig husbandry: the hard work of changing the course of a river. Science, Technology and Human Values 33 (4), 480-507.

Braverman, H., 1974. Labour and Monopoly Capital: The Degradation of Work in the Twentieth Century. Monthly Review Press, New York.

Braudel, F., 1993. A History of Civilizations. Penguin Books.

Burger, T., 1986. Multidimensional problems: a critique of Jeffrey Alexander's theoretical logic in sociology. The Sociological Quarterly 27 (2), 273-292.

Burrell, G., Morgan, G., 1979. Sociological Paradigms and Organizational Analysis. Heinemann, Porthsmouth, NH

Butter, F.A.G., den Hofkes, M.W., 2006. A neo-classical economics viewpoint on technological transitions. In: Olsthoorn, X., Wieczoreck, A.J. (Eds.), Understanding Industrial Transformation: Views from Different Disciplines. Springer, Dordrecht, NL, pp. 141-162.

Callon, M., 1980. The state and technical innovation: a case-study of the electrical vehicle in France. Research Policy 9 (4), 358-376.

Callon, M., Laredo, P., Rabeharisoa, V., 1992. The management and evaluation of technological programs and the dynamics of techno-economic networks: the case of the AFME. Research Policy 21 (3), 215-236.

Callon, M., Latour, B., 1992. Don't throw the baby out with the Bath school: a reply to Collins and Yearley. In: Pickering, A. (Ed.), Science as Practice and Culture. The University of Chicago Press, Chicago and London, pp. 343-368.

Callon, M. (Ed.), 1998. The Laws of the Market. Blackwell, Oxford.

Callon, M., 2002. Technology, politics and the market: an interview with Michel Callon, conducted by Andrew Barry and Don Slater. Economy and Society 31 (2), 285-306.

Cattani, G., 2006. Technological pre-adaptation, speciation, and emergence of new technologies: how Corning invented and developed fiber optics. Industrial and Corporate Change 15 (2), 285-318.

Chandy, R.K., Tellis, G.J., 1998. Organizing for radical product innovation: the overlooked role of willingness to cannibalize. Journal of Marketing Research 35 (4), 474-487.

Christensen, C., 1997. The Innovator's Dilemma: When New Technologies Cause Great Firms to Fail. Harvard Business School Press, Boston, MA.

Collins, H.M., Yearley, S., 1992. Journey into space. In: Pickering, A. (Ed.), Science as Practice and Culture. The University of Chicago Press, Chicago and London, pp. 369-389.

Collins, R., 1975. Conflict Sociology: Toward an Explanatory Science. Academic Press, New York.

Collins, R., 1986. Is 1980s sociology in the doldrums? The American Journal of Sociology 91 (6), 1336-1355.

Collins, R., 1994. Four Sociological Traditions. Oxford University Press, Oxford.

Cyert, R.M., March, J.G., 1963. A Behavioral Theory of the Firm. Prentice-Hall, Englewood Cliffs, NJ.

DiMaggio, P.J., 1995. Comments on "What theory is not". Administrative Science Quarterly 40 (3), 391-397.

Dosi, G., 1982. Technological paradigms and technological trajectories: a suggested interpretation of the determinants and directions of technical change. Research Policy 6 (3), 147-162.

Eisenhardt, K.M., 2000. Paradox, spirals, ambivalence: the new language of change and pluralism (Introduction to special issue). The Academy of Management Review 25 (4), 703-1703.

Elias, N., 1978. What is Sociology? Hutchinson, London.

Elzen, B., Geels, F.W., Green, K. (Eds.), 2004. System Innovation and the Transition to Sustainability: Theory, Evidence and Policy. Edward Elgar, Cheltenham.

Emirbayer, M., 1997. Manifesto for a relational sociology. American Journal of Sociology 103 (2), 281-317.

Eyerman, R., Jamison, A., 1991. Social Movements: A Cognitive Approach. The Pennsylvania State University Press, University Park, PA.

Fagerberg, J., Verspagen, B., 2009. Innovation studies: the emerging structure of a new scientific field. Research Policy 38 (2), 218-233.

Foster, R.N., 1986. Innovation: The Attacker's Advantage. MacMillan, London.

Foucault, M., 1970. The Order of Things: An Archaeology of the Human Sciences. Random House, New York.

Freeman, J.H., Carroll, G.R., Hannan, M.T., 1983. The liability of newness: age dependence in organizational death rates. American Sociological Review 48 (5), $692-710$.
Freeman, C., Perez, C., 1988. Structural crisis of adjustment, business cycles and investment behaviour. In: Dosi, G., Freeman, C., Nelson, R., Silverberg, G., Soete, L. (Eds.), Technical Change and Economic Theory. Pinter, London, pp. 38-66.

Freeman, C., 1992. A green techno-economic paradigm for the world economy. In: Freeman, C. (Ed.), The Economics of Hope. Pinter Publishers, London, pp. 190-211.

Freeman, C., Louçă, F., 2001. As Time Goes By: From the Industrial Revolutions to the Information Revolution. Oxford University Press, Oxford.

Gavetti, G., Levinthal, D., 2000. Looking forward and looking backward: cognitive and experiential search. Administrative Science Quarterly 45 (1), 113-137.

Geels, F.W., 2002. Technological transitions as evolutionary reconfiguration processes: a multi-level perspective and a case-study. Research Policy 31 (8/9), 1257-1274.

Geels, F.W., 2004. From sectoral systems of innovation to socio-technical systems: insights about dynamics and change from sociology and institutional theory. Research Policy 33 (6/7), 897-920.

Geels, F.W., 2006. Major system change through stepwise reconfiguration: a multi-level analysis of the transformation of American factory production (1850-1930). Technology in Society 28 (4), 445-476.

Geels, F.W., Schot, J.W., 2007. Typology of sociotechnical transition pathways. Research Policy 36 (3), 399-417.

Geels, F.W., 2007. Feelings of discontent and the promise of middle range theory for STS: examples from technology dynamics. Science, Technology \& Human Values 32 (6), 627-651.

Geels, F.W., Verhees, B., 2008. Cultural legitimacy struggles in technological transitions: the ups and downs of Dutch nuclear energy (1945-1986). In: Paper Presented at 4S/EASST Conference, 20-23 August, Rotterdam, the Netherlands.

Geels, F.W., 2009. Foundational ontologies and multi-paradigm analysis, applied to the socio-technical transition from mixed farming to intensive pig husbandry (1930-1980). Technology Analysis \& Strategic Management 21 (7).

Genus, A., Coles, A.-M., 2008. Rethinking the multi-level perspective of technological transitions. Research Policy 37 (9), 1436-1445.

Giddens, A., 1984. The Constitution of Society: Outline of the Theory of Structuration. University of California Press, Berkeley.

Gioia, D.A., Pitre, E., 1990. Multiparadigm perspectives on theory building. Academy of Management Review 15, 584-602.

Gramsci, A., 1932 (1975). In: Lynne Lawner (Ed.). Letters from Prison, Antonio Gramsci, Harper Colophon, New York.

Greenwood, R., Hinings, C.R., 1996. Understanding radical organizational change: bringing together the old and the new institutionalism. Academy of Management Review 21 (4), 1022-1054.

Grinyer, P., McKiernan, P., 1990. Generating major change in stagnating companies. Strategic Management Journal 11, 131-146.

Hajer, M.A., 1995. The Politics of Environmental Discourse: Ecological Modernization and the Policy Process. Clarendon Press, Oxford.

Hård, M., 1993. Beyond harmony and consensus: a social conflict approach to technology. Science, Technology \& Human Values 18 (4), 408-432.

Hård, M., 1994. Technology as practice: local and global closure processes in dieselengine design. Social Studies of Science 24, 549-585.

Hess, D.J., 2005. Technology and product-oriented movements: approximating social movement studies and science and technology studies. Science, Technology \& Human Values 30 (4), 515-535.

Holland, J.H., 1995. Hidden Order: How Adaptation Builds Complexity. Helix books/Perseus books, Cambridge, MA.

Holling, C.S., 2001. Understanding the complexity of economic, ecological and social systems. Ecosystems 4 (5), 390-405.

Horgan, J., 1995. From complexity to perplexity. Scientific American 272 (6), 104-109.

Horkheimer, M., Adorno, T., 1947. Dialectic of Enlightenment. Herder and Herder, New York.

Jordan, A., 2008. The governance of sustainable development: taking stock and looking forwards. Environment and Planning C 26 (1), 17-33.

Katz, E., Rothenberg, D., Light, A. (Eds.), 2000. Beneath the Surface: Critical Essays in the Philosophy of Deep Ecology. MIT Press, Cambridge, MA.

Kauffman, S., 1995. At Home in the Universe: The Search for Laws of SelfOrganization and Complexity. Oxford University Press, USA.

Kemp, R., 1997. Environmental Policy and Technical Change. Edward Elgar, Cheltenham.

Kitschelt, H., 1986. Political opportunity structures and political protest: antinuclear movements in four democracies. British Journal of Political Science 16, 57-85.

Kolb, D.A., 1984. Experiential Learning: Experience as the Source of Learning and Development. Prentice-Hall, Englewood Cliffs.

Lant, T.K., Mezias, S.J., 1992. An organizational learning model of convergence and reorientation. Organization Science 3 (1), 47-71.

Latour, B., 1987. Science in Action. Harvard University Press, Cambridge, MA.

Latour, B., 1996. Aramis or the Love of Technology. Harvard University Press, Cambridge, MA.

Law, J., 1999. After ANT: complexity, naming and topology. In: Law, J., Hassard, J. (Eds.), Actor Network Theory and After. Blackwell, Oxford, UK, pp. 1-14.

Levinthal, D.A., 1992. Surviving Schumpeterian environments: an evolutionary perspective. Industrial and Corporate Change 1 (3), 427-443.

Levinthal, D.A., 1998. The slow pace of rapid technological change: gradualism and punctuation in technological change. Industrial and Corporate Change 7 (2), 217-247. 
Levy, D.L., Newell, P.J., 2000. Oceans apart? Business responses to the environment in Europe and North America. Environment 42 (9), 8-20.

Lévi-Strauss, C., 1963. Structural Anthropology. Basic Books, New York.

Lewis, M.W., Grimes, A.J., 1999. Metatriangulation: building theory from multiple paradigms. The Academy of Management Review 24 (4), 672-690.

Lounsbury, M., Glynn, M.A., 2001. Cultural entrepreneurship: stories, legitimacy, and the acquisition of resources. Strategic Management Journal 22 (6-7), 545-564.

Lukes, S., 1974. Power: A Radical View. Macmillan, London.

Mahoney, J., 2004. Revisiting general theory in historical sociology. Social Forces 83 (2), 459-489.

Malerba, F., 2006. Innovation and the evolution of industries. Journal of Evolutionary Economics 16 (1), 3-23.

Markard, J., Truffer, B., 2008. Technological innovation systems and the multi-level perspective: towards an integrated framework. Research Policy 37 (4), 596-615.

Martin, B.R., Bell, M., Callon, M., Grupp, H., Kodama, F., Kuhlmann, S., Fleming, L., Von Tunzelmann, N., Powell, W., 2009. EES and the continuing evolution of Research Policy. Research Policy 38 (5), 695-699.

McCarthy, J., Zald, M., 1977. Resource mobilization and social movements. American Journal of Sociology 82, 1212-1241.

Meadowcroft, J., 2005. Environmental political economy, technological transitions and the state. New Political Economy 10 (4), 479-498.

Mintzberg, H., Ahlstrand, B., Lampel, J., 1998. Strategy Safari: A Guided Tour Through the Wilds of Strategic Management. The Free Press, New York.

Morel, B., Ramanujam, R., 1999. Through the looking glass of complexity: the dynamics of organizations as adaptive and evolving systems. Organization Science 10 (3), 278-293.

Morlacchi, P., Martin, B., 2009. Emerging challenges for science, technology and innovation policy research: a reflexive overview. Research Policy 38 (4) 571-582.

Mouzelis, N., 1995. Sociological Theory: What Went Wrong? Diagnoses and Remedies. Routledge, London.

Nelson, R.R., Winter, S.G., 1982. An Evolutionary Theory of Economic Change. Belknap Press, Cambridge, MA.

Oliver, C., 1992. The antecedents of deinstitutionalization. Organization Studies 13 (4), 563-588.

Parsons, T., 1951. The Social System. Free Press, Glencoe, IL.

Poole, M.S., Van de Ven, A.H., 1989. Using paradox to build management and organization theories. Academy of Management Review 14 (4), 562-578.

Porter, M., 1980. Competitive Strategy: Techniques for Analyzing Industries and Competitors. Free Press, New York.

Porter, M., 1991. Towards a dynamic theory of strategy. Strategic Management Journal 12 (Winter Special Issue), 95-117.

Powell, W., DiMaggio, P. (Eds.), 1991. The New Institutionalism in Organizational Analysis. The University of Chicago Press, Chicago.

Puller, S.P., 2006. The strategic use of innovation to influence regulatory standards. Journal of Environmental Economics and Management 52 (3), 690-706.

Rammert, W., 1997. New rules of sociological method: rethinking technology studies. British Journal of Sociology 48 (2), 171-191.

Reckwitz, A., 2002. Towards a theory of social practices: a development in culturalist thinking. European Journal of Social Theory 5 (2), 243-263.

Rip, A., 1992. A quasi-evolutionary model of technological development and a cognitive approach to technology policy. Rivista di Studi Epistemologici e Sociali Sulla Scienza e la Tecnologia 2, 69-103.

Rip, A., Kemp, R., 1998. Technological change. In: Rayner, S., Malone, E.L. (Eds.), Human Choice and Climate Change. Battelle Press, Columbus, OH, pp. 327-399.

Ritzer, G., 1980. Sociology: A Multiple Paradigm Science. Allyn and Bacon, Boston.

Romer, P.M., 1986. Increasing returns and long-run growth. Journal of Political Economy 94 (5), 1002-1037.

Røpke, I., 2001. New technology in everyday life: social processes and environmental impact. Ecological Economics 38, 403-422.

Rothaermel, F., 2001. Incumbent's advantage through exploiting complementary assets via interfirm cooperation. Strategic Management Journal 22 (6-7), 687-699.

Rotmans, J., Kemp, R., Van Asselt, M., 2001. More evolution than revolution: transition management in public policy. Foresight 3 (1), 15-31.

Rugman, A.M., Verbeke, A., 1998. Corporate strategies and environmental regulations: an organizing framework. Strategic Management Journal 19(4), 363-375.
Schön, D.A., 1983. The Reflective Practitioner: How Professionals Think in Action. Basic Books, New York.

Schot, J.W., 1992. The policy relevance of the quasi-evolutionary model: the case of stimulating clean technologies. In: Coombs, R., Saviotti, P., Walsh, V. (Eds.), Technological Change and Company Strategies: Economic and Sociological Perspectives. Academic Press, London, pp. 185-200.

Schot, J.W., Geels, F.W., 2007. Niches in evolutionary theories of technical change: a critical survey of the literature. Journal of Evolutionary Economics 17 (5), 605-622.

Schumpeter, J.A., 1934. The Theory of Economic Development: An Inquiry into Profits, Capital, Credit, Interest, and the Business Cycle. Harvard University Press, Cambridge, MA

Schumpeter, J.A., 1939. Business Cycles: A Theoretical, Historical and Statistica Analysis of the Capitalist Process. McGraw-Hill, New York.

Scott, W.R., 1995. Institutions and Organizations. Sage Publications, Thousand Oaks, CA.

Shove, E., 2003. Comfort, Cleanliness and Convenience: The Social Organization of Normality. Berg Oxford.

Shove, E., Pantzar, M., 2005. Consumers, producers and practices: understanding the invention and reinvention of Nordic Walking. Journal of Consumer Culture 5 (1) 43-64.

Shove, E., Walker, G., 2007. CAUTION! Transitions ahead: politics, practice and sustainable transition management. Environment and Planning A 39 (4), 763 770.

Smith, A., Stirling, A., Berkhout, F., 2005. The governance of sustainable sociotechnical transitions. Research Policy 34, 1491-1510.

Smith, A., 2005. The alternative technology movement: an analysis of its framing and negotiations of technology development. Human Ecology Review 12 (2), 106-119.

Spillman, L. (Ed.), 2002. Cultural Sociology. Blackwell Publishers, Massachusetts, USA.

Stirling, A., 2007. Deliberate futures: precaution and progress in social choice of sustainable technology. Sustainable Development 15, 286-295.

Suchman, M.C., 1995. Managing legitimacy: strategic and institutional approaches Academy of Management Review 20 (3), 571-611.

Swidler, A., 1986. Culture in action: symbols and strategies. American Sociologica Review 51 (2), 273-286.

Teece, D.J., Pisano, G., Shuen, A., 1997. Dynamic capabilities and strategic management. Strategic Management Journal 18 (7), 509-533.

Tripsas, M., 1997. Unravelling the process of creative destruction: complementary assets and incumbent survival in the typesetter industry. Strategic Management Journal 18 (S1), 119-142.

Tushman, M.L., Rosenkopf, L., 1992. Organizational determinants of technological change: towards a sociology of technical evolution. In: Cummings, L.L., Staw, B.M. (Eds.), Research in Organizational Behavior, 14. JAI Press Inc., Greenwich, CT, pp. 311-347.

Tushman, M.L., O’Reilly, C.A., 1996. Ambidextrous organizations: managing evolutionary and revolutionary change. California Management Review 38 (4), 8 30.

Unruh, G.C., 2000. Understanding carbon lock-in. Energy Policy 28, 817830.

Van den Berg, A., 1998. Is sociological theory too grand for social mechanisms? In: Hedström, P., Swedberg, R. (Eds.), Social Mechanisms: An Analytical Approach to Social Theory. Cambridge University Press, Cambridge, pp. 204-237.

Van den Bergh, J.C.J.M., Bruinsma, F.R. (Eds.), 2008. Managing the Transition to Renewable Energy: Theory and Practice from Local, Regional and Macro Perspectives. Edward Elgar, Cheltenham.

Van Lente, H., 1993. Promising Technology: The Dynamics of Expectations in Technological Development. Eburon, Delft

Weber, M., 1946. [1922-1923]. The social psychology of the world religions. In: Gerth, H.H., Wright Mills, C. (Eds.). From Max Weber. Oxford University Press, New York, pp. 267-301.

Weick, K.E., 1979. The Social Psychology of Organizing. Addison-Wesley, Reading, MA.

Wiskerke, J.S.C., Van der Ploeg, J.D., 2004. Seeds of Transition: Essays on Novelty Production, Niches and Regimes in Agriculture. Van Gorcum, Assen. 